\title{
Entre el entusiasmo y la indiferencia. Expectativas y acciones de la baja y mediana burocracia frente a la Reforma del Servicio Civil en dos ministerios peruanos $\left(^{*}\right)$
}

\section{Between enthusiasm and indifference. Expectations and actions of low- and-medium-rank bureaucrats about the Civil Service Reform in two Peruvian ministries}

\author{
Jair Alva Mendoza (**) \\ Pontificia Universidad Católica del Perú \\ ORCID: 0000-0002-8929-5655
}

\section{Giovanni Arriola Laura (***) \\ Pontificia Universidad Católica del Perú \\ ORCID: $\underline{0000-0001-8729-9727}$}

\section{Vivian Ramos Coronado (****) Pontificia Universidad Católica del Perú ORCID:0000-0003-1115-1368}

Fecha de recepción: 26 de agosto

Fecha de aceptación: 13 de noviembre

\section{ISSN en línea: $2415-2498$}

Alva, J.; G. Arriola y V. Ramos (2018) «Entre el entusiamo y la indeferencia. Expectativas y acciones de la baja y mediana burocracia frente a la Reforma del Servicio Civil en dos ministerios peruanos». Politai: Revista de Ciencia Política, Año 9, segundo semestre, № 17: pp. 90-118.

DOI: https://doi.org/10.18800/politai.201802.003

\footnotetext{
* Agradecemos la valiosa ayuda de Noam López y el Grupo de Investigación en Políticas Públicas por su aporte a este trabajo. También a Luis García por sus agudos comentarios, y todas las personas que nos ayudaron con contactos para realizar las entrevistas y las(os) mismas(os) entrevistadas(os). Finalmente, agradecemos la ayuda de Stephany Calisaya y Valerie Marchena en la elaboración de este artículo.

**Estudiante de pregrado de la carrera de Ciencia Política y Gobierno de la Pontificia Universidad Católica del Perú (PUCP). Miembro del Grupo de Investigación en Políticas Públicas.

***Estudiante de pregrado de la carrera de Ciencia Política y Gobierno de la Pontificia Universidad Católica del Perú (PUCP). Miembro del Grupo de Investigación en Políticas Públicas.

****Estudiante de pregrado de la carrera de Ciencia Política y Gobierno de la Pontificia Universidad Católica del Perú (PUCP). Miembro del Grupo Coordinador Nacional de la Campaña 100 Millones Perú contra el trabajo infantil.
} 


\section{Sumilla}

El servicio civil peruano ha sido caracterizado como un elemento de la baja capacidad del Estado peruano por estar inmerso en un desorden normativo (multiplicidad de regímenes laborales) y por su ausente planificación. Así, desde el año 2008, se inició el proceso de reforma del servicio civil peruano, el cual ha tenido como uno de sus principales objetivos garantizar el acceso meritocrático a los puestos públicos del Estado peruano. Sin embargo, a dos años de culminar su meta trazada (2020), aún no se ha implementado el tránsito de los diferentes regímenes laborales al régimen de la Ley Servir. A partir de ello, el presente estudio busca comprender las expectativas y acciones de la baja y mediana burocracia peruana sobre el efecto que tendría la reforma del servicio civil en las dinámicas laborales que se han desarrollado en estos espacios de trabajo. Para lograr dicho objetivo, se selecciona dos ministerios: Educación e Interior, por ser dos entidades que iniciaron los procedimientos del tránsito al nuevo régimen laboral en 2014, pero que a enero de 2018 han logrado un avance diferente. De esta forma, se describen las dinámicas laborales de la baja y mediana burocracia; se explican las causas de la actual diferencia en el avance de la reforma en dichos ministerios del Estado; y, finalmente, se analiza la posición y las acciones de la baja y mediana burocracia frente a la implementación de la reforma del servicio civil. A partir de una revisión de documentación y entrevistas semiestructuradas, se encuentra que los servidores de los niveles de burocracia estudiados muestran un acuerdo con los objetivos generales de Servir; sin embargo, presentan dos posiciones adversas a la reforma: 1) perciben que Servir no ha informado adecuadamente sobre los efectos de la reforma en su trabajo; y 2) que la implementación de la reforma no mejorará sustancialmente la meritocracia ya existente en los ministerios estudiados. De esta manera, el estudio contribuye a comprender a la burocracia frente a reformas institucionales internas del Estado peruano.

Palabras clave: Servir, burocracia, Reforma del Servicio Civil, Minedu, Mininter 


\begin{abstract}
Peruvian civil service has been characterized as an element of low capability of the Peruvian state for being immersed in normative disorder (plenty of labor regimes) and for its non-existent planification. Thus, since 2008, a process of reforming the Peruvian civil service was started, said process has had as one of its main objectives to guarantee meritocratic access to public job positions of the Peruvian state. Nevertheless, with only two years left to achieve its main goal (2020), the transit of the different labor regimes to the regime of La ley Servir has not been has not been implemented yet. Having that on account, this study seeks to understand the expectations and actions of the low and medium bureaucracy on the effect that the civil service reform will have in the labor dynamics that have been developing in these workspaces To achieve said objective, two ministries are chosen: Education and Interior, for being two entities that started the procedures of the transit to the new labor regime in 2014, but to January of 2018 both had achieved a different progress. Thus, the labor dynamics of the low and medium bureaucracy are described; the causes of the current difference in the progress of the reform in both ministries are explained; and, finally the position and actions of the low and medium bureaucracy against the implementation of the civil service reform are analyzed. Starting with a examination of the documents and semi-structured interviews, we find out that the servers of the levels of bureaucracy studied show an agreement with the general objectives of Servir; nevertheless, they have two adverse positions to the reform: 1) both of them perceive that Servir has not informed correctly about the effects of the reform in their work; and 2) the implementation of the reform will not improve substantially the existing meritocracy in both ministries. This way, the study contributes to understand bureaucracy in front of internal institutional reforms of the Peruvian state.
\end{abstract}

Keywords: Servir, bureaucracy, Civil Service Reform, Ministry of Education, Ministry of the Interior 


\section{Introducción}

"Tenemos que jugarnos por Servir, queremos dar la muestra que esto es algo beneficioso para los trabajadores, nosotros seríamos totalmente inconsistentes si proponemos algo y no es el mismo MEF que está detrás de esto" (Carlos Oliva, Ministro de Economía y Finanzas, 2 de agosto de 2018, Agencia Peruana de Noticias Andina). Las grandes reformas usualmente son analizadas desde los que las dirigen, dejando de lado las dinámicas que existen entre los actores que son objetos de dichas reformas. El presente artículo se centra en esto último.

¿Cuáles son las expectativas de la mediana y baja burocracia peruana frente a la reforma del Servicio Civil? ¿Cuáles han sido las principales acciones que han realizado los burócratas frente al avance de la Reforma? En general, ¿Cómo ha sido la relación entre la Reforma y la burocracia peruana a cuatro años de su inicio? El presente trabajo responde a estas cuestiones analizando el avance de la reforma en dos ministerios peruanos: Interior y Educación, por ser dos entidades que iniciaron los procedimientos del tránsito al nuevo régimen laboral en 2014, pero que a enero de 2018 han logrado un avance diferente. El objetivo central es comprender las expectativas y acciones de la baja y mediana burocracia peruana sobre el efecto que tendría la reforma del servicio civil en las dinámicas laborales que se han desarrollado en estos espacios de trabajo.

La metodología utilizada se basa en el análisis de información recogida de los servidores públicos a través de entrevistas semi-estructuradas. En estas entrevistas se ha preguntado sobre su carrera y estabilidad laboral, sus expectativas sobre la implementación de la reforma del servicio civil, y la acciones que llevarían a cabo de implementarse tal reforma. Los sujetos de estudio han cumplido las condiciones de ser servidores entre los puestos de apoyo, especialista, ejecutivo o directivo superior de los ministerios mencionados, con un periodo mínimo de trabajo en la institución de cuatro años. En ese sentido, se buscó realizar la entrevista a 10 servidores, 5 de cada uno de los ministerios.

\begin{tabular}{|c|c|c|}
\hline Puesto & Ministerio de Educación & Ministerio del Interior \\
\hline Especialista & 3 & 1 \\
\hline Ejecutivo/a & 2 & - \\
\hline Asesor & & \\
\hline Total & 5 & \multicolumn{2}{|c|}{1} \\
\hline
\end{tabular}

Cuadro 1. Cuadro de puestos de las personas entrevistadas. Elaboración: propia.

\footnotetext{
${ }^{1}$ Se aplicó y utilizó la información brindada por un asesor que laboró más de cinco años en ambos ministerios, por lo que la información brindada sirve para contrastar con la información de los demás informantes.
} 
Sin embargo, como se muestra en el Cuadro 1, para la recolección de información se pudo grabar y utilizar la información brindada para la investigación a 7 servidores. El principal problema para conseguir las entrevistas fue el periodo de tiempo de se requería para ser sujeto de estudio (mínimo cuatro años) y la disponibilidad para con la investigación. En ese sentido, los hallazgos no permiten una generalización, ni realizar una comparación entre ambos ministerios; pero sí permiten una aproximación a las expectativas de los servidores peruanos.

La estructura del texto consta de cinco partes, incluida esta introducción. La segunda parte, discute los principales paradigmas en la administración pública bajo dos principales enfoques: la clásica weberiana y la Nueva Gerencia Pública; ambas nacidas como parte de procesos económicos. La primera en el marco de la industrialización y la segunda en el auge del neoliberalismo. De esta manera, se discute si es que un cambio de estructura organizativa realmente implica una mejora en la administración pública. Finalmente, se ubican las reformas del servicio civil en Latinoamérica, en el marco de dichos paradigmas.

La tercera parte del texto discute la reforma del servicio civil en el Perú, la cual nace en el marco del Tratado de Libre Comercio con los Estados Unidos de América, siendo ésta la ventana de oportunidad para una reforma bajo el estilo de la Nueva Gerencia Pública. En la cuarta parte, se analiza la información obtenida a través de las entrevistas aplicadas a los servidores públicos. De esta manera, el capítulo se divide en tres subacpítulos: (1) la situación laboral de los servidores, (2) las expectativas de los servidores sobre la reforma del servicio civil, y (3) las acciones que ejercerían de llevarse a cabo la reforma del servicio civil. Finalmente, se desarrollan las conclusiones del texto, la cual recoge el contexto de la reforma del servicio civil como una reforma característica del paradigma de la Nueva Gerencia Pública, los avances que ha tenido hasta la fecha y cómo se posicionan los servidores civiles frente a ello.

\section{Rompiendo paradigmas}

La reforma del servicio civil peruano se posiciona, epistemológicamente, como el tránsito de un sistema weberiano a un sistema basado en la Nueva Gerencia Pública. En otras palabras, el servicio civil peruano a cargo de la Autoridad Nacional del Servicio Civil (Servir), aspira a formar un sistema laboral cuya elección meritocrática esté basada en los concursos públicos de méritos con un estilo empresarial, donde los aspirantes deben de cumplir una serie de requisitos académicos y profesionales para que puedan ocupar los cargos públicos. Dichos cargos públicos deben ser cuidadosamente específicos en funciones, de manera que sean parte esencial de un sistema completo donde los puestos y procesos estén claramente definidos.

En tal sentido, esta sección buscará responder a dos preguntas. Primero: ¿cuál es la diferencia sustancial entre el enfoque de la Nueva Gerencia Pública y el enfoque clásico weberiano?; y, segundo: ¿es la Nueva Gerencia Pública, buena per sé? Es decir, se señalará las variaciones entre los dos enfoques burocráticos que han tenido más impacto en la forma de organización de los Estados y se discutirá 
críticamente si la llamada Nueva Gerencia Pública ${ }^{2}$ contiene elementos suficientes para considerarla como un enfoque necesariamente mejor que el modelo weberiano. Además, se añade una última sección en donde se señalan algunos problemas de estos enfoques adaptados a Estados poscoloniales como los latinoamericanos.

\section{De la Burocracia Weberiana a la Nueva Gerencia Pública}

La burocracia es un término relativamente nuevo si lo comparamos con el de sujeto político (Vergara y Rodríguez, 2016). Mientras que el origen del primer término se encuentra ligado al nacimiento del Estado moderno; específicamente al proceso de centralización del poder (Martínez, 2016); el segundo término ha tenido un desarrollo desde los textos filosóficos-políticos de la antigua Grecia. En este apartado se describe dos de los enfoques burocráticos históricamente predominantes: el de la burocracia weberiana y el de la Nueva Gerencia Pública; haciendo énfasis en los procesos económicos que acompañaron (o causaron) su apogeo y las principales diferencias que resaltan entre ellas.

Los dos principales enfoques burocráticos discutidos en este apartado, han ido a la par de —o son productos de - grandes cambios socioeconómicos. En primer lugar, el enfoque weberiano surge como una necesaria forma de organización estatal frente al proceso de industrialización de las sociedades occidentales; y, en segundo lugar, el enfoque gerencial nace producto de la crisis del Estado de bienestar, y el auge del neoliberalismo alrededor del mundo. (Trelles, 2009; Vergara y Rodríguez, 2016).

De este modo, como señala Petrella (2007) la burocracia emerge producto de la necesidad de administrar "una organización compleja en una sociedad moderna" (2007: s/n). Weber hace notar perfectamente esta relación al explicar el origen de la burocracia racional y señalar la existencia de un "paralelismo evidente entre la mecanización de la industria y la proliferación de las formas burocráticas de la organización” (Petrella 2007: s/n). En síntesis, las nuevas dinámicas económicas obligan a que el Estado genere nuevas formas de organizarse.

Así, la necesidad de reformar a los sujetos al servicio del Estado es producto de lo que ya se ha venido mencionando: el proceso de industrialización en la segunda mitad del siglo XIX (Restrepo, 2009). Además de ello, estas reformas se plantearon como una solución al estado patrimonialista: la idea central es que el empleado público dejaría de ser un servidor de la corona para ser un funcionario del Estado para el desarrollo de este y no de la nobleza (Martínez, 2005).

A partir de ello, la creación del servicio civil de carrera dentro del Estado pretendía "marginar a los políticos del campo de la administración del personal y eliminar el padrinazgo político, llegando a establecerse como principio que el servicio civil fuera un instrumento obediente e imparcial de la soberanía estatal, y un intérprete e implementador de la ley y de las políticas públicas" (Restrepo, 2009: 169).

\footnotetext{
${ }^{2}$ Más adelante argumentamos que la Reforma del Servicio Civil adopta este enfoque.
} 
Para alcanzar dicho objetivo, la principal medida adoptada por los estados fue la creación de un sistema de acceso laboral al aparato estatal; siendo la meritocracia la principal variable a considerar. Además, este cuerpo debía de seguir una lógica de jerarquía, dependiente de un manual de funciones, dentro de un sistema de remuneraciones y que su medio de subsistencia material provendría, principalmente, de su servicio al Estado (Grindle 2012; Petrella 2007; Vergara y Rodríguez, 2016). En síntesis, es un cuerpo compacto, con lógicas racionales bien establecidas al servicio del Estado.

Este paradigma burocrático cambió en los años 70’ y 80' producto de la crisis de los Estados de Bienestar alrededor del mundo. Las principales críticas a la concepción weberiana de la burocracia fueron que poseía una extremada rigidez de sus actuaciones, un excesivo formalismo en el análisis y que sus tomas de decisiones se encontraban vinculadas excesivamente al reglamento (Gómez Bahillo, 2006).

En este contexto, un nuevo enfoque organizacional de la burocracia cobra fuerza alrededor del mundo. De nuevo, junto a un proceso económico, esta vez de agresiva liberalización económica (el neoliberalismo), se introduce el enfoque de la cultura gerencial dentro de la administración pública. Este nuevo enfoque burocrático "exalta como factores culturales; lo privado, el individualismo y la rentabilidad” (Vergara y Rodríguez, 2016: 122).

Las principales características de la denominada Nueva Gerencia Pública (NGP) son "el énfasis en los resultados y en la medición del desempeño, el monitoreo y la evaluación; el acento en la reducción de costos; la insistencia en la reducción del tamaño del gobierno; la promoción, para ese fin, de la privatización, la tercerización y la descentralización de servicios provistos por el Estado” (Restrepo, 2009: 175).

Así, este modelo que puede ser descrito como el de un Estado gerencial, se enfoca en la eficiencia y, sobre todo, "en la creencia de que las reformas procedimentales y estructurales harían posible tener un gobierno que trabajara mejor y costará menos" (Restrepo, 2009: 178). Puede ser, incluso, que este considere como su objetivo el ciudadano y se incluya sistemas de aparente participación ciudadana; no obstante su núcleo duro está constituido por:

el gerenciamiento de carácter empresarial, el presupuesto y la evaluación por resultados y desempeño, la mayor autonomía de las unidades ejecutoras junto con mayor libertad de elección de medios de sus agentes administradores la remuneración con base en el desempeño, la creación de mercados internos entre las dependencias estatales y la ponderación de costo frente a la prestación del servicio por el sector privado (Restrepo, 2009: 177-178).

En este sentido, ¿qué diferencia a la Nueva Gestión Pública de la weberiana? En concreto, su énfasis en la eficacia, la eficiencia y la economía; siendo el modelo empresarial su punto de partida. Aunque también se considera elementos del clásico modelo weberiano, tales como la meritocracia, la adecuada asignación de sueldos y la funcionalidad de cada cargo; estos tienen como objetivo hacer al Estado más "eficiente". Esto produce que los ciudadanos sean considerados como clientes del sistema político. 
No obstante, el enfoque de la Nueva Gerencia Pública descrita hasta el momento es la que se asemeja más a la visión "neoempresarial", enfoque que viene de la corriente "neo pública", que en esencia, tiene la misma finalidad que el de la NGP empresarial pero que pone, o mejor dicho, añade, la atención en los ciudadanos y la ética pública ${ }^{3}$. Como señala Ramió (2001), "se refuerza el concepto de ciudadanía para que permita la expresión activa de las opiniones. El concepto de ciudadanía ha de servir para, mediante un discurso abierto y pluralista, recrear la legitimidad política en la Administración Pública” (2001: 4).

\section{Entonces... ¿Es la nueva gerencia pública, buena per se?}

Como se mencionó, la fórmula de la NGP nació en el apogeo del neoliberalismo, específicamente durante el gobierno de Margareth Thatcher en la década de 1980 cuando, para afrontar la severa crisis económica, se buscó sanear las instituciones estatales de una grave corrupción impregnada a todo nivel. De esta manera, coherentemente con los ideales neoliberales, la solución se encontró en el sector privado y las herramientas que este utiliza (Gálvez 2017: 41-42, Barzelay 2013: 114-115).

La NGP se posiciona entonces, como la solución a los problemas de los que ha sufrido el Estado bajo la burocracia weberiana: ineficiencia, corrupción y lentitud. Junto al concepto de "buen gobierno", esta nueva organización busca ser más eficiente que la burocracia weberiana (Schröder s/f). Sin embargo, aquella visión tiene vacíos metodológicos y empíricos que impiden una visión netamente optimista de aquel nuevo paradigma. A continuación se desarrollan tres razones que sustentan dicha posición.

En primer lugar, la visión más pragmática y economicista del paradigma post-burocrático que es la NGP, donde la gestión de recursos se perfila como un sistema que va a satisfacer las necesidades de un usuario-cliente, puede constituirse como una "camisa de fuerza" puesto que a largo plazo puede ser incapaz de generar los objetivos de eficiencia trazados, debido a que el exceso de profesionalización puede terminar siendo incompatible con el desempeño de cargos técnicos en la estructura del Estado (Vergara y Rodríguez 2016). De esta forma, se retornaría al estado que la visión gerencial busca erradicar: ineficiencia.

Por otro lado, la visión gerencial parte de una lectura universalista de los problemas administrativos (burocracias con intereses propios o capturas sistemáticas de poderes económicos del aparato estatal); sin embargo, existen realidades nacionales que escapan a la lectura de la NGP. Como se mencionó líneas arriba, fue a partir de regímenes políticos denominados como "Westminster" donde nació la teoría de la nueva gerencia pública, por lo que una generalización a realidades distintas como las latinoamericanas sería muchas veces "pretencioso" (Arellano 2004). De esta forma, se han importado modelos occidentales que lograron una exitosa reforma del servicio civil en sus contextos particulares, por lo que no existe certeza que la importación de la NGP se adecúe con el mismo éxito en contextos nooccidentales.

\footnotetext{
${ }^{3}$ Más adelante, se señalará que la Reforma del Servicio Civil Peruano adopta parte de este enfoque. Es decir, aunque en el fondo se enmarca dentro de la Nueva Gerencia Pública, hace énfasis en la atención al ciudadano, la ética y la transparencia.
} 
En tercer lugar, Álvaro Gálvez (2017), argumenta, que la NGP importa un diseño organizacional de tipo empresarial, evidenciado en una estructura basada en una misión, una visión y unos objetivos donde la columna vertebral es el plan estratégico. De esta manera, el Estado, bajo la NGP, basa sus intervenciones en la medición de indicadores sociodemográficos que permiten plantear objetivos nacionales. Sin embargo, de esa forma se genera una mirada simplista de la realidad ${ }^{4}$. Una visión de ese tipo excluye dinámicas que no son parte del sistema organizacional antes descrito, lo cual se ha denominado la "visión de túnel del Estado" (Gálvez 2017: 86). Aquellas dinámicas son, por ejemplo, culturas organizacionales de entidades estatales, que son formas de organización que escapan a la medición de indicadores y a normas impuestas.

Por todo lo anterior, no se busca plantear una imagen fatalista de la administración pública bajo esta nueva forma de organización. Por el contrario, se plantea que los Estados modernos debido a su extensión territorial y peso demográfico, se ha visto en la necesidad de buscar mediciones que permitan algún tipo de lectura de la realidad nacional; o, por otro lado, se evidencia la necesidad de importar modelos administrativos que pudiesen ayudar a solucionar problemas como la corrupción o cooptación de poderes fácticos. Sin embargo, tampoco se debe ser indiferente a los matices que la NGP puede generar en la reforma de los servicios civiles en estados con historias y realidades complejas y distintas al modelo occidental, como son los estados latinoamericanos. En otras palabras, la NGP no es la fórmula a la ineficiencia e ineficacia de la que adolece muchas veces la gestión pública.

\section{Algunas reflexiones de las reformas del servicio civil en Latinoamérica}

Hasta ahora se ha señalado cuáles han sido los dos principales enfoques históricos de organización estatal. No obstante, es necesario precisar que estos modelos responden a realidades diferentes a la latinoamericana y que, producto de ello, su adaptabilidad a los estados caracterizados como poscoloniales ha sido, en reiteradas veces, problemática. En este sentido, en este último apartado se señalan algunos problemas identificados en los procesos de reforma administrativa en países latinoamericanos.

Una factor importante que caracteriza a los estados latinoamericanos es la herencia colonial y su carácter patrimonialista (Martín Barbero 2010, Grindle 2012. Cotler 2014, Resico 2015). Debido a ello, diversos autores han considerado que las reformas estatales que provienen de modelos occidentales (europeos o estadounidenses) presentan una serie de problemas al momento de implementarse en países como los latinoamericanos.

Un ejemplo de ello es Brasil. La experiencia de las reformas aplicadas en este país da cuenta que no es suficiente la creación legal y parámetros institucionales para realizar una reforma burocrática. Ramírez de la Cruz (2010) señala que existen tres puntos fundamentales a trabajar en la administración pública

\footnotetext{
4 Véase Primera Evaluación del Plan Estratégico de Desarrollo Nacional (PEDN) 2018. Estudio de Ceplan que busca evaluar resultados de política nacional a través de "progresos de indicadores".
} 
brasileña: capacitaciones, cambios en las estructuras de las organizaciones y el mejoramiento de las capacidades. Por otro lado, el caso ecuatoriano muestra que pese a la existencia de una legislación del servicio civil, en la década de 1980 sólo el $2.5 \%$ de los empleados públicos habían ocupado sus puestos a través de concurso de méritos (Grindle 2012: 148). Esto quiere decir que las reformas deben de considerar las dinámicas en las que se encuentra inmersa la burocracia y no sólo en los marcos legales/institucionales en las que trabaja.

Merilee Grindle (2012) demuestra que en américa latina, incluido Perú, pese a una gran base legal que norma el servicio civil, dicho intento por instaurar una burocracia weberiana meritocrática, antipatrimonialista, ha fracasado. Las élites políticas han encontrado la manera de sortear las normas, para garantizar que su entorno político ocupe puestos del Estado, de manera que ayudan a conseguir las metas que estos se hayan trazado (sean públicas o personales). Particularmente, sobre el caso peruano, antes de implementada la reforma del servicio civil, los niveles de meritocracia era, junto a todos los países de la región (a excepción de Brasil) muy bajos, donde los esfuerzos para limitar la discreción en la contratación, promoción o despido de los puestos públicos no tuvo éxito (Grindle 2012: 147-155).

Por último, Ramírez de la Cruz y García (2010) señalan que las reformas tienen ciertas particularidades en países emergentes como los latinoamericanos pues se encuentran inmersas en una vulnerabilidad macroeconómica. Así, cuando ocurren crisis económicas, los temas de modernización del Estado y evaluación del desempeño pasan a un segundo plano. De este modo, se produce un círculo vicioso: "no se institucionalizan las reformas, entonces no da resultados y como no da resultados, en la primera crisis se le ignora y se deja de lado. Esto a su vez provoca también que se pierda interés; una vez pasada la crisis, cuando se retoman, pierden el factor de novedad y es necesario buscar nuevos instrumentos de mejora" (Ramírez de la Cruz y García 2010: 448).

Reconocidas las diversas problemáticas de las reformas del servicio civil en Latinoamérica, a continuación, se realiza una evaluación de la Reforma del Servicio Civil en el Perú. Esta evaluación parte de un análisis del enfoque y la propuesta de la reforma de Servir y los avances que ha tenido hasta el momento. 


\section{La reforma del servicio civil en el Perú}

En esta sección, se argumenta que Servir responde — en gran medida — al enfoque de la Nueva Gestión Pública; aunque con ciertos matices a considerar. Es decir, que aunque en el fondo Servir nace con un enfoque empresarial de la NGP, ésta tiene variables de las llamadas corrientes neo públicas que hacen énfasis en la participación ciudadana y los canales de transparencia. Al final de la sección, se realiza un balance de los avances de dicha reforma.

\section{a) El nacimiento de Servir}

Existe un consenso de la baja calidad del servicio civil peruano. Principalmente, se señala su desorden normativo (existencia de diversos regímenes laborales), la ausencia de planificación y su baja capacidad institucional (Iacovello y Zuvani 2005, Iacovello 2011, Strazza y Azzolina 2011, Corrales 2012, Servir 2012, Vásquez y Matos 2015, Iacoviello y Chudnovsky 2015, Iacoviello 2015). Esto llevó a que, hasta el 2014, el Perú se ubique como uno de los países de América Latina con los peores índices en calidad de recursos humanos (BID 2004).

Fue a partir de 2008 que la posibilidad de firmar el Tratado de Libre Comercio (TLC) con Estados Unidos apuró la reforma del sistema burocrático peruano, creándose la Autoridad Nacional del Servicio Civil (Servir) -Decreto Legislativo 1023. Asimismo se creó el Cuerpo de Gerentes Públicos (Decreto Legislativo 1024), normas de capacitación y rendimiento para el sector público y el Fondo de Fortalecimiento del Capital Humano (D. Leg. 1025), el régimen especial para los gobiernos subnacionales (D. Leg. 1026), y el Régimen de Contratación Administrativa de Servicios, CAS (D. Leg. 1057). Sin embargo, la reforma se puso en marcha recién en 2014, con la entrada en vigencia de la Ley de Servicio Civil (LSC), Ley N 30057.

En ese sentido, se fijaron dos objetivos fundamentales de la LSC. En primer lugar, establecer progresivamente un régimen único y de forma exclusiva para las personas que prestan servicios en las entidades públicas del Estado y para aquellas encargadas de gestionarlo. Y, en segundo lugar, las entidades públicas del Estado alcancen mayores niveles de eficacia y eficiencia; presten servicios de calidad a través de un mejor Servicio Civil; así como promover el desarrollo de las personas que lo integran (El Peruano 2013, Iacoviello 2015: 9).

\section{b) ¿Cuál es el enfoque que adopta Servir?}

El artículo sostiene que el enfoque adoptado por Servir es el de la Nueva Gerencia Pública señalado líneas arriba. No obstante, el enfoque de NGP tiene varias aristas y se encuentra matizada por la influencia de otras corrientes públicas. En ese sentido, Servir además de recoger la esencia de la NGP, adquiere algunos elementos de las corrientes neo públicas que ponen el énfasis en el servicio al ciudadano (no al cliente) y en generar medios de transparencia y ética pública. 
Según los propios documentos de Servir, esta entidad se crea en el marco de decretos legislativos por parte del Estado peruano que fomentaba la facilitación del comercio, la promoción de la inversión privada, la mejora del marco regulatorio, fortalecimiento institucional y simplificación administrativa; la modernización del Estado, entre otro temas (Servir 2012: 96). El punto fundamental en ello es que la autoridad encargada de la reforma administrativa peruana nace con un impulso e interés economicista, enmarcada en la implementación del Acuerdo de Promoción Comercial entre Perú y Estados Unidos.

En segundo lugar, según el documento oficial de Servir (2012), hasta el año 2012, esta entidad se dedicó a trabajar en, lo que consideró, los cuatro aspectos más urgentes, a saber, la capacitación, el rendimiento, la profesionalización del cuerpo directivo y la resolución de controversias.

Así, en torno al primer tema señala que su objetivo es "lograr el desarrollo técnico de las personas al servicio del Estado, con el fin de satisfacer los requerimientos de los ciudadanos y el logro de los objetivos institucionales de la entidad a la que pertenecen” (2012: 99). Mientras que en el caso del segundo, el documento señala que "la evaluación del desempeño es un proceso obligatorio, integral, sistemático, continuo y demostrable del conjunto de actividades, aptitudes y rendimiento del personal en el cumplimiento de sus objetivos y metas" (2012: 100).

En estas dos citas textuales, se encuentra el énfasis en el carácter de eficacia y eficiencia. Mientras por un lado se hace énfasis en el desarrollo técnico de los burócratas, por el otro, se señala que el rendimiento del personal parte del cumplimiento en los objetivos que tiene la entidad estatal en la que se encuentre.

En tercer lugar, incluso la norma en torno a la reforma del servicio civil señala en sus dos objetivos centrales $^{5}$. Su prioridad es la meritocracia y la mejora de los ingresos de la burocracia peruana. De nuevo, su énfasis está en los elementos de NGP: eficacia y eficiencia.

Por último, es necesario mencionar la influencia del Ministerio de Economía y Finanzas (MEF) en las reformas aplicadas en el Perú. Está comprobado que muchas de las grandes acciones realizadas por el Estado peruano dependen en gran medida del MEF. Vergara y Encinas señalan esta fuerte influencia economicista a través de tres estrategias: la primera es el candado, esto es reglamentos internos, mandatos constitucionales, acuerdos internacionales y comerciales, entre otros. Un ejemplo es el artículo 60 de Constitución del Perú o los límites legales al gasto público en año de elecciones (2016: 171-175)

La segunda estrategia es la de la infiltración, esto es que los tecnócratas neoliberales logran entrometerse en otros ámbitos del aparato estatal en pos de mantener el poder del MEF dentro del Estado, ejemplos claros son lo ocurrido en el Ministerio de Desarrollo e Inclusión Social (MIDIS), creado por en el gobierno de Ollanta Humala, donde tecnócratas neoliberales lograron infiltrarse para soslayar los efectos de este ministerio como el de ser un fuerte contrapeso al MEF (Encinas y Vergara 2016: 171-175)

\footnotetext{
${ }^{5}$ Véase: https://www.servir.gob.pe/servicio-civil/ley-del-servicio-civil/
} 
Por último, la tercera estrategia usada es que estos tecnócratas se acomodan a los diversos cambios, como lo sucedido con la creación del MIDIS (dándole un enfoque neoliberal de política social) y con la el Ministerio del Ambiente (recortando sus facultades estratégicamente en los diversas medios de control que éste ejercía) (Encinas y Vergara 2016: 171-175).

Así pues, serán estas estrategias utilizadas por los tecnócratas neoliberales las cuales harán permanecer un régimen de acuerdo a su visión neoliberal. La Reforma Del Estado, entonces, no escaparía a ello, pues como bien se señala en los documentos oficiales, Servir:

está realizando estudios, conjuntamente con el MEF, que permitan plantear los lineamientos para iniciar un proceso de reforma del sistema remunerativo, el que deberá implementarse de manera gradual por razones de responsabilidad fiscal y en función del avance en el desarrollo de instrumentos e institucionalidad en la definición de perfiles, selección, capacitación y evaluación del desempeño. (Servir 2012: 101).

La Reforma, entonces, se adapta al modelo de la Nueva Gerencia Pública; sin embargo, contiene elementos de la corriente neo-pública que le pone énfasis al servicio al ciudadano e implementar canales institucionales en pos de la transparencia. Así, por ejemplo, en la descripción del tema sobre Funcionarios y empleados de confianza, se señala que se debe "definir requisitos mínimos para la profesionalización de los funcionarios públicos y empleados de confianza y establece[r] reglas claras para lograr una gestión transparente, eficaz, eficiente y orientada al ciudadano" (Servir 2012: 105). Es decir, además de la eficacia y eficiencia, se exige un compromiso con el ciudadano. En lo que sigue del escrito, se realiza un balance de los avances de la Reforma del Servicio Civil peruano.

\section{c) Avances y obstáculos de la Reforma del Servicio Civil}

El Cuerpo de Gerentes Públicos fue la primera muestra de un avance en la mejora del servicio civil peruano. Iacoviello (2011) y Corrales (2012) señalan que la creación y la implementación de este cuerpo es la principal explicación a la mejora de los "subsistemas de recursos humanos, del avance de los indicadores de calidad del servicio civil, del inicio de la profesionalización del segmento directivo" (2012: 20), entre otros.

Esta mejora del servicio civil peruano ha ido aumentando en los últimos años. Los estudios de Iacovello y Cudnovsky (2015) Iacovello (2015) y Cortés y Prieto (2015) continúan señalando que la principal fortaleza de esta reforma se encuentra en el Cuerpo de Gerente Públicos, aunque se reconoce que "Servir habiendo logrado importantes avances mediante el Cuerpo de Gerentes Públicos como una de las estrategias para fortalecer a la administración pública, emprendió una ambiciosa reforma de mayor escala para atender los problemas descritos en el servicio civil peruano de manera integral: la reforma del Servicio Civil" (Cortés y Prieto 2015: 5).

Ahora bien, con el fin de que las entidades obtengan una mejora institucional y no solo un cambio en el régimen laboral de sus trabajadores cada entidad debe llevar un proceso de preparación de cuatro fases: primero, preparación de la entidad; segundo, el análisis situacional de la entidad; tercero, la aplicación 
de mejoras internas; y finalmente, la implementación del nuevo régimen (Cortés y Prieto, 2015). Servir ha señalado estas cuatro etapas por las que cada entidad debe transitar para pasar al régimen del servicio civil. La primera es el Inicio de Incorporación al proceso de Tránsito y preparación de la entidad, la cual consiste en conformar una comisión encargada del tránsito, y es la etapa en la que se realizan las acciones de comunicación "que permitan garantizar que todos los servidores conozcan la ruta que su entidad deberá seguir para transitar al nuevo régimen del servicio civil” (Página web de Servir).

La segunda etapa, llamada Análisis Situacional, consiste en identificar los puestos y procesos a mejorar dentro de la entidad. Para ello se realiza un mapeo de los puestos, de los procesos y de las mejoras. Al finalizar esta etapa, las entidades están en condiciones de solicitar la resolución de Inicio de Proceso de Implementación del Nuevo Régimen del Servicio Civil.

En la tercera etapa se empieza con la Mejora Interna, es decir, se determinan la dotación de recursos humanos para la entidad y se empieza a diseñar los nuevos documentos de gestión. La determinación de dotación consiste en "definir la estructura de los recursos humanos de la entidad y la composición de los puestos (grupo, familia, rol y nivel o categoría), así como determinar la cantidad de puestos y posiciones que se requiere para su adecuado funcionamiento" (Página web de Servir). Por último, en la cuarta etapa se llevan a cabo los concursos públicos de selección bajo el nuevo Régimen. En sí, esta es la parte de la implementación de la Reforma.

En general, el proceso de tránsito de las entidades se encuentran en una posición medio/alta en el Índice de Desarrollo del Servicio Civil (IDSC). Dicho índice es medido por el Banco Interamericano de Desarrollo (BID), el cual es calculado a través de cinco índices, a saber, Índice de Eficiencia, Índice de Mérito, Índice de Consistencia Estructural, Índice de Capacidad Funcional e Índice de Capacidad Integradora.

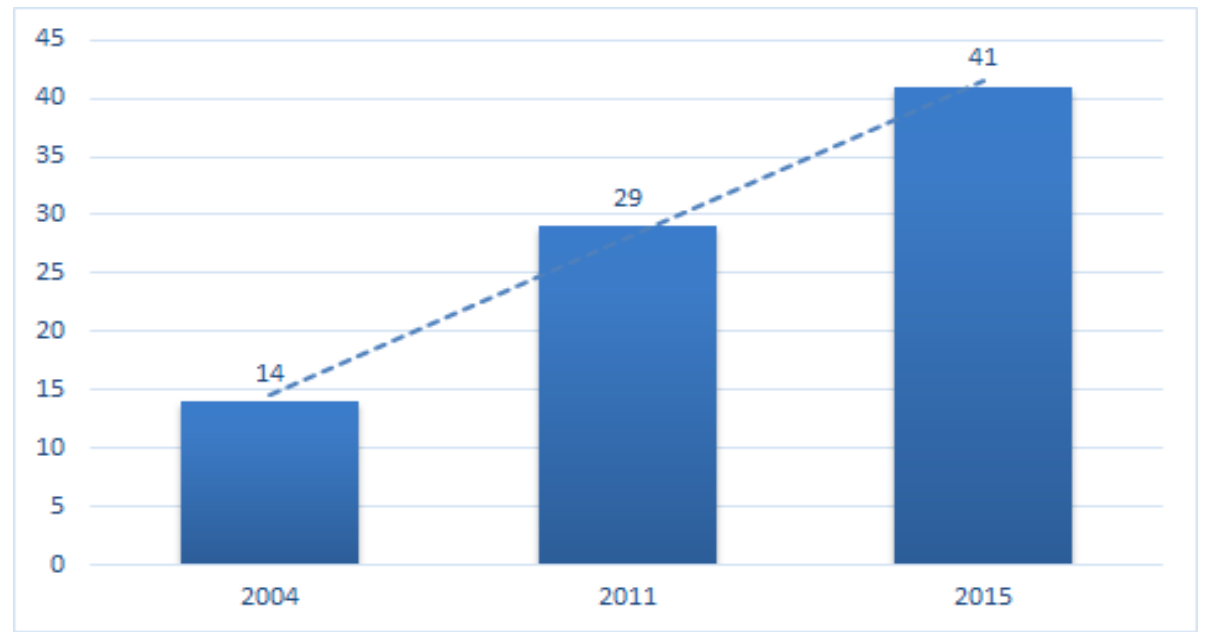

Gráfico 1. Evolución del índice de Desarrollo del Servicio Civil. Elaboración propia en base a Servir 2016 
Como se observa en el Gráfico 1, el IDSC se ha incrementado en 27 puntos (en una escala del 0 al 100) con lo cual supera el promedio latinoamericano. A partir de dicha evidencia, Servir (2016) argumenta que dicho aumento es significativo debido a la creación del ente rector del Sistema Administrativo de Gestión de Recursos Humanos del Estado (Servir 2016: 7). Asimismo, dado que la implementación de la reforma del servicio civil únicamente se ha basado en el Cuerpo de Gerentes Públicos, se argumenta que gracias a dicho cambio en la administración es que se ha mejorado en los indicadores medidos por el BID.

Hasta abril de 2018, son 391 las entidades las que han iniciado el tránsito a la LSC. Dicha proporción es reducida teniendo en cuenta que las entidades del Estado son más de 2900 entre entidades.

Asimismo, son 52 las entidades con "Resolución de inicio"; es decir con paso a la etapa 3 de implementación. Estas varían entre ministerios, gobiernos regionales, municipalidades provinciales, Organismos Constitucionalmente Autónomos (OCA's); Organismos Públicos Descentralizados (OPD); Organismo Público Ejecutor (OPE); Organismo Técnico Especializado (OTE); Programas, Proyectos y otros. Predominan en ellos, los Organismos Técnicos Especializados (OTE); e instituciones nacionales (47). Estas entidades representan el $13.29 \%$ de las 391 en inicio a la LSC.

Juan Carlos Cortés Carcelén, presidente ejecutivo de la Autoridad Nacional del Servicio Civil - Servir, precisó que al 2015 eran 14 las entidades presentaron el mayor avance por encontrarse en el tercer paso del tránsito, tales como: Servir, Ministerio de Economía, IGP, Ministerio de Defensa, Ministerio de Justicia, ONP, Serfor, Ceplan, Osinfor, Devida, Concytec, Susalud, Provías Nacional y la Agencia de Compras de las Fuerzas Armadas (SERVIR, 2015)

En la misma línea, sobre entidades de tipo A, que también están conformadas por órganos rectores como los ministerios. Es preciso señalar que son 47 entidades las que han iniciado con la "Etapa 3: Mejora interna", de las cuales el 25,5\%, es decir, 12 entidades, son ministerios. Es decir, es el tercer grupo más amplio después de los Organismos Públicos Ejecutores (OPE)(13); Organismos Técnicos Especializados (OTE) (14). En este proceso, es posible entender que el cuerpo burocrático es fundamental. Tal como señala Arévalo (2017) el liderazgo administrativo, participación y voluntad inicial son elementos centrales en el avance del proceso; sin embargo, existen factores técnicos que obstaculizan la implementación de la reforma. Para Torres, una variable que puede influir en que una entidad, como los ministerios, avancen en la reforma son por ejemplo, la cantidad de tiempo que lleva en tránsito la institución o la percepción de la complejidad de las herramientas de tránsito por parte del equipo operativo (2016:118).

A todo esto, se ha evidenciado ciertas reticencias en la implementación de la reforma en las entidades peruanas. Ello es visible en las formas de resistencia internas que han sido documentadas por Delgado (2017) en instituciones con procesos de transición de tiempo intermedio como el Ministerio de Transportes, el Ministerio de Educación y como El Ministerio de Economía y Finanzas. Esto en cuanto a la falta de estrategias comunicacionales sobre las preocupaciones de mejoras salariales, estabilidad laboral, evaluaciones de desempeño y capacidad laboral. De otro lado, se ha evidenciado la necesidad de orientación y tercerización del proceso de elaboración de herramientas para el tránsito esto por la amplia carga laboral de las entidades públicas en el caso del Ministerio de Salud, Ministerio de Educación, 
Ministerio de Transportes y Comunicaciones y Ministerio de Justicia. Sin embargo, se hace necesario ahondar en las dinámicas de otros ministerios para un entendimiento amplio de la brecha de implementación.

Por otro lado, Torres (2016) ahonda en las variables que más influyen a que un ministerio avance en la reforma. Su estudio encuentra como variables principales, "la cantidad de personas que presta servicios en el ministerio, la cantidad de años que lleva en tránsito el ministerio, la percepción de complejidad de las herramientas del tránsito por parte del equipo operativo y la posición jerárquica del puesto que se desempeña como 'champion' en el ministerio" (Torres 2016: 118).

Asimismo, Arévalo (2017) estudia la implementación del plan piloto del modelo de Gestión del Rendimiento aplicado en Serfor. La autora argumenta que el liderazgo administrativo, los acuerdos y la voluntad inicial, las estrategias de comunicación y la participación amplia y la amplitud en la convocatoria de actores favorecieron la implementación del plan. No obstante, fueron los factores técnicos los que obstaculizaron la continuación de dicha implementación.

Por último, Delgado (2017) identifica "los factores que afectan el nivel de avance en la coordinación, de las entidades públicas en la implementación de la LSC promovida por Servir entre el período 20142015" (2017: 6). La autora encuentra que Servir se ha concentrado más en diseñar sus herramientas que implementarlas y que existe deficiencias técnicas por parte de las unidades estatales (muchas de ellas terminan contratando consultorías).

En síntesis, el proceso de reforma del servicio civil tiene mejoras claras producto de la creación del Cuerpo de Gerentes Públicos y por los avances en los dos primeros procesos de la Reforma. Los estudios para evaluar los avances de la reforma son aún limitados y se han concentrado en variables institucionales, evaluando principalmente las características de las instituciones, ya sean sus ventajas y/o limitaciones.

\section{¿Qué nos dicen los protagonistas?}

El presente capítulo relaciona los temas antes tratados con las expectativas y actitudes de los servidores civiles de los ministerios de educación e interior. Dichos ministerios fueron escogidos porque ambos iniciaron el tránsito al nuevo régimen de servicio civil en 2014 (Interior en enero y Educación en abril). De ambos ministerios, al 2018, solo el Ministerio del Interior tiene Resolución de Inicio, lo cual significa que está lista para iniciar con la última etapa del tránsito. De esta manera, aunque la cantidad de entrevistas realizadas no permite generalización, se espera encontrar alguna diferencia en las posiciones de los servidores públicos entre ambos ministerios, debido a las diferencias en los avances de sus entidades en la implementación de la reforma. 


\section{a) Condiciones laborales}

Ahora bien, ¿bajo qué condiciones institucionales y/o legales se encuentran laborando los burócratas de los regímenes laborales actual? En el Estado peruano encontramos una variedad de regímenes laborales. $\mathrm{Al}$ respecto, Boyer Carrera señala que:

"coexisten en el Estado peruano varias modalidades contractuales: la carrera administrativa (D. Leg. 276), el régimen privado (D. Leg. 728), los contratos administrativos de servicios (D. Leg. 1057 de 2008, modificado en 2011), la gerencia pública (D. Leg. 1024), los funcionarios altamente calificados (Decreto de Urgencia 051-2011), el Fondo de Apoyo Gerencial (Decreto Ley 25650-1992), y la locación de servicios. Esta diversidad genera inequidades en la distribución de los deberes (un servidor de carrera presenta un mayor número de incompatibilidades que un CAS) y, especialmente, de los derechos (compensaciones, vacaciones, aguinaldos o gratificaciones)" (Boyer Carrera, 2014).

Con la Ley de Servicio Civil, aquellos burócratas que pertenezcan a los regímenes de los Decretos Legislativos $\mathrm{N}^{\circ} 276$ y $\mathrm{N}^{\circ} 728$, tendrán la potestad de transitar al nuevo régimen del servicio civil voluntariamente. Entonces: ¿cuáles son los beneficios y/o costos de cambiarse de un régimen a otro?

En primer lugar, el régimen laboral de 276 corresponde a la carrera administrativa dentro del Estado peruano. Dicho régimen se caracteriza por ser un sistema cerrado; pues en ella, "el ingreso a la carrera se realiza por el nivel más bajo del grupo ocupacional y la promoción de los servidores públicos en los diferentes niveles depende del cumplimiento de requisitos previamente determinados, que incluyen antigüedad en el puesto, capacitación y evaluación" (Servir 2012: 20). Una particularidad de este régimen es que incluye un punto en la que se señala el carácter de estabilidad temporal ilimitada del que disponen los burócratas. Es decir, una clara ventaja de pertenecer a este régimen es la continuidad laboral, sin importar el nivel de capacitación de los burócratas.

En segundo lugar, el régimen laboral 728, también conocida como el Régimen laboral de la Actividad Privada, nace en "un contexto de reforma del Estado centrada en la creación de entidades que funcionan como enclaves de excelencia ligadas a las reformas económicas" (Servir: 2012: 48). Una características primordial de este régimen es que produjo la creación de las islas de eficiencias en el Estado peruano, ya que planteó "escalas remunerativas distintas al sistema único de remuneraciones e incorporaron personal altamente capacitado en posiciones de responsabilidad, siendo exonerados del requisito de ascender peldaño a peldaño en la estructura de niveles" (2012: 48). Este régimen permite que cada "entidad aprueba su propio reglamento interno, sus propios grupos ocupacionales y sus propios niveles al interior de cada grupo" (2012: 50). Así, la ventaja de quedarse en este régimen radica en una mayor ganancia de conocimiento y sueldo.

Por último, promulgada en junio del 2008, el régimen especial de contratación administrativa de servicios (CAS), "constituye una modalidad contractual laboral temporal especial, propia del Estado" (2012: 56). En este contexto, es preciso resaltar que "el régimen CAS supone una contratación temporal por un periodo restringido a un año fiscal, renovable” (2012: 57).

Como ya se ha visto a lo largo del escrito, el objetivo de la reforma de Servir es -entre otras cosasponer orden a este diverso régimen laboral; el cual tendrá un impacto en la mejora de la calidad de los 
servicios que el Estado brinda a los ciudadanos y en el mejoramiento de ingresos de la mayoría de los servidores públicos e incentivar su crecimiento personal y profesional en la administración pública.

Entonces, dado que el burócrata es el principal actor en este proceso de reforma, se realizó entrevistas semiestructuradas a servidores de ministerios para así poder comprender cuáles son las expectativas que estos tienen en torno a la reforma. Este acápite se centra en tres cuestiones: la primera está relacionada con la manera en cómo llegaron a ocupar el puesto en el que se desenvuelven, la segunda se refiere al desempeño de actividades no estipuladas en el contrato y por último se abordará el tema de la presencia de los sindicatos en los ministerios mencionados.

En cuanto a la primera cuestión, no hay un consenso en cuanto a la manera en la que los servidores llegaron a ocupar el puesto en el que se desenvuelven; encontramos especialistas senior en el Ministerio de Educación que a pesar de que llevan más de 10 años trabajando para el Estado, su contrato es renovado cada 3 o 6 meses en el mejor de los casos; a algunos les pesa esta inestabilidad y para otros es cuestión de costumbre, tal como manifestó uno de los entrevistados cuando se le preguntó sobre su rotación dentro del Ministerio: "Yo tuve que postular a cada uno de los puestos porque a pesar de que tengo casi 20 años, yo soy contratado y casi cada 3 meses me renuevan el contrato. Ya estoy acostumbrado". Empero, también se tiene el caso de servidores que han ingresado por locación de servicios: "Yo vine primero incorporado por locación de servicios como un gran número de trabajadores, después vino la ley del sistema administrativo CAS hicieron una adecuación del contrato y tuve la continuidad de servicio".

El caso del Ministerio del Interior es similar al del Ministerio de Educación, pues se han hallado servidores que han ingresado a sus puestos por cargo de confianza o que son parte del régimen laboral 276. El primero es el caso de un asesor del gabinete ministerial, quien manifestó lo siguiente: "Bueno, me llamaron. Hace dos años, me pasaron (sic) la voz un exjefe que tuve que ya estaba trabajando en el Mininter [Ministerio del Interior] y me dijo que necesitaba un profesional en el gabinete que vea temas del sistema educativo [...]".

Y el segundo caso pertenece al de un especialista, quien afirma que el régimen laboral al que pertenece, no le ofrece estabilidad laboral al servidor: "soy del régimen laboral 276, no tengo contrato, soy trabajador de plano o servidor de plano, pero mi régimen me hace sentir seguro". En este punto, no se observa diferencia, el caso de contraste (el asesor) tiene una estabilidad laboral diferente. Esta se basa en la confianza que se le renueve en el gabinete, mientras que los servidores de rangos más bajos tienen que ser contratados bajo periodos cortos de tiempo. Pero aunque los modos sean diferentes, el fondo es similar: ambos pueden no ser recontratados fácilmente.

Hasta este momento, se ha hallado que los servidores del Estado de ambos Ministerios llegan al puesto que desempeñan de diversas formas; algunos por un régimen laboral CAS en el que han logrado mantenerse más de 4 años, algunos incluso casi 20 años. Otros pertenecen al régimen laboral 276 y llevan en la Institución más de 30 años. Pero, ¿todos estos servidores realizan actividades más allá de las 
estipuladas en su contrato a pesar de tener diferente régimen laboral? La respuesta es afirmativa; por el contrario, las tensiones surgen en la percepción que tienen los servidores sobre esta segunda cuestión más allá del régimen laboral al que pertenecen. El caso de un servidor del Ministerio de Educación quien realiza las labores extras con entusiasmo afirma: “[...] estas cosas adicionales que hago son más interesantes, cuando hay que hacer algún informe, me lo pasan a mí porque ya tengo expertise, manejo el marco normativo, además soy escritor y tengo buen nivel de redacción [...] soy multifacético". Sin embargo, también se encuentra la visión de otra servidora del Ministerio de Educación para quien su trabajo debería acabar a las cinco de la tarde, pero que en sus más de 4 años trabajando para el Estado nunca ha podido hacerlo debido a que a lo largo del día le llegan tareas que ella no tenía planificada realizar:

“yo tengo mi planificación diaria, pero al final del día término haciendo más de lo que había planificado [...] y si me voy a las cinco, mis compañeros me miran mal, ni siquiera mi jefe, esa es una de las cosas que no me gustan del Perú. Piensan que si te vas temprano es porque no tienes nada que hacer, mientras que en otros países si te quedas más tiempo en el trabajo significa que eres ineficiente porque no puedes cumplir en tu horario normal, las tareas designadas".

De esa forma, se encuentra que independientemente de los cargos ocupados se maneja una cultura organizacional característica del Estado peruano; pero que no está exenta de tensiones. La diferencia está en cómo toman los servidores estas tareas extras. En el caso del Ministerio del Interior, se evidencia que un servidor también toma las labores extra que realiza como un desafío y manera de aprendizaje diario porque "el tema de la jornada laboral de 8 horas es una formalidad, en la práctica no se da; por el espacio en el que trabajo puedo entrar antes de las 9 am como puedo no saber a qué hora me voy a ir. Veo puntos que no son de mi experiencia y tengo que aprender en ese momento y atender temas que no son para los que me contrataron y en algunos casos cumplir funciones de reemplazo, pero ahí está mi desafío $[\ldots]$ "..

Dichas manifestaciones muestran una cultura organizacional está basada en la imagen de un servidor martirizado. Puesto que aquel tiene que tener habilidades más allá de las que se requirieron para su contratación junto a una disponibilidad de trabajo más allá de las 8 horas. Por todo lo dicho, se argumenta que los servidores están enmarcados en un tipo de cultura de servicio exclusivo al Estado que no da mucho espacio al desarrollo personal de dichas personas.

Por último, en cuanto a la presencia o no de los sindicatos en los Ministerios estudiados; se encuentra que en ambos ministerios existen sindicatos pero que no están muy extendidos en la cultura organizacional de los sectores. En algunos casos, tampoco hay conocimiento sobre quiénes pertenecen al sindicato: "yo no formo parte de ningún sindicato, no sé ni siquiera si los CAS pueden ser parte, nunca he sido muy así de sindicalista, yo trabajo, hago lo que puedo y ya está". Aunque se observa que los sindicatos no han tienen una capacidad de arraigo poderosa, se ha encontrado evidencia que los sindicatos son hostiles a la reforma impulsada por Servir. 
Un informante del Ministerio de Educación, que pertenece al sindicato, narra lo siguiente:

“ellos siempre están pensando que esta [LSC] es una ley intervencionista, están pensando que probablemente esto va a significar un despido, hay ya un planteamiento de echarse a bajo la Ley en el Congreso. O sea, los gremios han interpuesto acciones de este tipo [...] no se ha puesto en la balanza qué opina el trabajador, no se ha practicado, no conozco ninguna encuesta para saber que opinan de la Ley"

De esta forma, se encuentra que los servidores, sufren de inestabilidad laboral en distintos niveles laborales. Todas las entrevistas muestran que la conciencia de que en cualquier momento podrían perder su puesto de trabajo es una imagen poderosa que deja claro el desorden laboral y lo perjudicial que es para un adecuado desenvolvimiento laboral. Finalmente, sobre la hostilidad de los sindicatos, se infiere una falencia en Servir de comunicar adecuadamente qué significa este nuevo tránsito y por qué sería bueno para el sector.

\section{b) Avance de la reforma e implicancias laborales}

En el presente acápite de analizará las relaciones tensas u optimistas. Para ello el trabajo se enfoca en 4 puntos: el primero es acerca de la información que ha brindado Servir a los servidores de los ministerios, seguidamente el trabajo se centra en lo que "piensa" el servidor acerca de la Reforma de Servicio Civil; es decir, si es que considera que ésta es necesaria y urgente; el tercer punto está relacionado con los cambios que han percibido los servidores dentro del Ministerio desde el 2014, fecha en la que ambos ministerios iniciaron el tránsito al nuevo régimen. Por último, el trabajo se enfoca en expectativas de los servidores sobre los avances o retrocesos que ha tenido la reforma a partir de los cambios de ministros.

En lo que se refiere a la información que ha brindado Servir a los servidores de los ministerios; a través de las entrevistas realizadas se evidencia que no ha habido una correcta comunicación, lo que ha ocasionado que se creen mitos en torno a la reforma tanto en el Ministerio de Educación como en el Ministerio del Interior. En algunos casos, cuando Servir brindaba capacitaciones y charlas informativas a los servidores, estas no lograban ser comprensibles para el público receptor, quienes se quedaban con varias dudas debido a que el personal de Servir no siempre se mostraba abierto o dispuesto a responderlas. Sin embargo, a pesar de lo anterior mencionado, se ha encontrado casos en los que los servidores quieren mantenerse informados sobre el proceso por el que atraviesa el Ministerio y cómo éste genera un impacto directo en ellos. Tenemos así el caso de servidores del Ministerio de Educación, quienes señalan que:

"hemos leído todos porque en nuestra oficina las normas que salen, las leemos, las comentamos porque tenemos que mantenernos al día, son 12 sistemas administrativos y todos los tenemos que manejar. Al menos las personas que tenemos más edad, tenemos esa práctica. Hay otras personas que solo se enfocan en su trabajo y no tratan de comprender los sistemas que se están implementando [...] he leído, pero si tú me haces un examen ahorita de eso, probablemente no responda."

Como se ha mencionado líneas arriba, también hay casos en los que los servidores del Ministerio de Educación señalan que efectivamente han tenido capacitaciones de Servir: 
"Sí, hemos tenido varias capacitaciones, nos plantearon que el tránsito es progresivo y que nos va a afectar a todos, pero personalmente yo no entendí más allá de eso".

"Recursos Humanos con Servir llevaron estas charlas, además todos los que entran a Minedu [Ministerio de Educación] o estando en el Minedu, pasamos por un programa básico donde te transmiten estos temas y además hacen unos trabajos sobre liderazgo, trabajo en equipo pero uno de los módulos básicos que todos tienen que hacer tiene que ver con lo laboral, regímenes, etc. Me parece que en el año 2015, empezaron las charlas"

El caso del Ministerio del Interior es diferente pues de los entrevistados, ninguno ha sido informado sobre la reforma por la que atraviesa el Ministerio:

"Lo único que sé es que Servir ha empezado a trabajar muy cerca con el área de recursos humanos del Mininter para las contrataciones de un programa que estamos implementado que se llama Auxiliares de Policía y que se estarían implementando los procesos de selección con la nueva normativa de Servir ya establecida, pero para el sector en sí, no [...] Sí, he escuchado que en otras entidades del Estado, Servir está tratando de implementar la nueva Ley. Hay comités transitorios, pero acá no"

Paradójicamente, el Ministerio del Interior es la entidad de los dos casos de estudio que más avanzada se encuentra en relación con los requisitos cumplidos. En ese sentido, se da cuenta de que a pesar de las deficiencias comunicacionales que tiene Servir, los servidores de ambos ministerios presentan predisposición por aprender acerca del proceso por el que atraviesan los ministerios en el que desarrollan sus funciones. Esto último conlleva a enfatizar la importancia que tiene la reforma para los servidores.

Los primeros hallazgos en cuanto al segundo punto muestran que hay un consenso entre los servidores de ambos Ministerios pues todos los entrevistados indicaron que urge la implementación de la Reforma, pero que al mismo tiempo hay ciertos temores basados en los mitos que se originan por la deficiente comunicación de Servir:

“[...] sí se debe unificar un solo régimen, porque conviven múltiples regímenes. Ahora, como la mayoría somos CAS existe un temor respecto a Servir, el cual no tiene nada que ver con evaluación porque hay gente capaz, profesional, el problema es el sueldo, no sabemos si un régimen único llevaría a bajar los sueldos a niveles que terminarían expulsándonos del sector público".

Por otro lado, añaden que:

"se debe implementar porque yo creo que hay mucho desorden dentro de todas las formas de contrato, tienes a los nombrados, los CAS, los de orden de servicio y hay bastantes diferencias en cuanto a horario y a salario. Pero la verdad no sé cómo se vaya a implementar pero si se implementa que sea de lo mejor".

Pese a lo anterior, el consenso sobre la reforma es claro: 
"Yo creo que sí es necesario, sobre todo para que haya una nivelación"

Del mismo modo, los servidores del Ministerio del Interior comparten la opinión de los servidores del Ministerio de Educación, al afirmar que:

"Por supuesto que es necesaria una reforma del servicio civil. Hay un tema, un problema que sufro todos los días que es la alta rotación del personal, entonces el hecho de que no importe en qué área estés, la gente cambia demasiado rápido [...] yo creo que por lo que he escuchado, lo que Servir dice que va a hacer, te va a permitir una carrera meritocrática, sostenible, permanente a largo plazo y eso sería una gran ventaja para este ministerio [...]"

Su colega continúa:

"Es necesaria, es urgente [...] habrán afectados, digo afectados porque no todos están convencidos de que la Ley Servir es beneficiosa"

Entonces, lo que se tiene son servidores de ambos Ministerios, no solo predispuestos a tener conocimiento sobre lo que implica la Reforma del Servicio Civil, sino que también resulta que para ellos, esta es necesaria para poder frenar la alta rotación del personal, y que exista una unificación de regímenes laborales; al mismo tiempo no se evidencia el temor a ser expulsados del sector público, por la presencia de la LSC; al contrario las entrevistas muestran el interés en su aplicación.

En relación con los cambios que han percibido los servidores a partir del 2014, año en el que ambos Ministerios iniciaron el tránsito al nuevo régimen. En este tercer punto, se halla que ninguno de los servidores entrevistados ha percibido algún cambio significativo en el área en que trabaja. Por ejemplo, los servidores del Ministerio de Educación han respondido lo siguiente:

"Sí, ha sido un proceso administrativo. Ha habido gerentes de Servir pero que han venido de fuera del ministerio, han pasado todo el proceso y han entrado al ministerio y les ha faltado la experiencia que se adquiere estando en la gestión. Los resultados no necesariamente han sido significativos, algunas veces pueden cometer las mismas faltas de manera más técnica, más refinada, más experimentada. El cambio fue neutral”.

Se colega añade:

"No, todavía no cambia nada porque estamos en proceso, avanzando en lento. De repente este año tenemos algunas incorporaciones, pero no nos ha afectado a nosotros"

Y la respuesta de los servidores del Ministerio del Interior ha sido la siguiente:

"Yo creo que todo sigue funcionando igual. Conozco funcionarios que tienen ahí años. La parte administrativa, la manera cómo se contrata la gente, la alta rotación, contratación a dedo en algunos casos. Muchas cosas que contradicen lo que la Ley Servir vende [...]” 
"Con sinceridad, y eso que trabajo en el sistema, no. Por varias razones: el ministerio del interior es una entidad muy volátil políticamente. Entonces hoy podemos tener un ministro y a ese ministro nadie le garantiza que pueda tener una gestión mínima de 6 meses, o un año. Y hemos tenido años de gobierno donde en 365 días hemos llegado tener hasta 4 ministros o más ministros de un mes. Entonces es muy complicado poder mantener una continuidad [...]"

Estas últimas citas sobre la alta rotación dirigen el estudio al cuarto y último punto del acápite: avances y retrocesos de la reforma a partir de cambios de ministros. Existen consenso en la opinión de los servidores del Ministerio de Educación y del Ministerio del Interior; pues estos están convencidos de que la alta rotación de ministros ha frenado el avance de la Reforma:

"Evidentemente para cualquier cambio se necesita liderazgo fuerte [...] En el Mininter yo saqué la cuenta porque voy como mi tercer ministro y dije: ¿qué pasa acá? De Toledo hasta la fecha ha habido ya 23, 24 ministros del Interior. Tienes un ministro en promedio cada siete meses. Y si le agregamos a eso que es una persona que no conoce mucho el sector y su tiempo de aprendizaje va a ser más largo, súmale a eso la coyuntura, la complejidad del sector. Entonces ya cuando está quinto, sexto mes que está aprendiendo algo, se va. Y estoy casi seguro que la mayor parte de su tiempo ha sido ocupado por la coyuntura. Y bueno, al tema doméstico que podría ser implementar una nueva ley de servicio civil por lo que he visto cerca, no creo que se le haya dado la atención necesaria. Es más, creo que ni siquiera aparece en la agenda del ministro".

Su colega añade:

"Entonces llega un ministro, pero ese ministro ni siquiera ha tomado conocimiento de lo que ha recibido y ya lo está cambiando y el cambio de ministro o de alta dirección involucra a que los demás estamentos, vale decir, los funcionarios de confianza que tienen a su cargo los órganos de línea cambien. Entonces, los criterios que en algún momento se pudieron haber planteado para un proceso de incorporación no se dan y se aletargan".

En cambio, en el Ministerio de Educación, se encuentra opiniones variadas:

"Mira, yo creo que el tiempo de adecuación o de transición para implementar la norma dentro de los ministerios varía dependiendo de la coyuntura, si es que tiene muchos problemas, si es que hay actividad $[\ldots] "$

Por otro lado,

"Yo creo que sí, cada gestión viene con una prioridad. Puede ser que para un ministro sea prioridad obras por impuestos y para otro es prioridad obras públicas. No paran, pero sí desaceleras".

En suma, se afirma que Servir no ha informado de manera adecuada la implementación de la LSC; pero pese a eso, todos los servidores están de acuerdo con la necesidad de un sistema administrativo meritocrático y un régimen civil único. Por otro lado, los servidores no perciben cambios sustanciales en sus entidades debido al proceso de implementación de la reforma o la contratación de Gerentes Públicos. Con estos últimos, por el contrario, no encuentran diferencia en comparación con un servidor de otro 
régimen y sistema de contratación. Finalmente, los servidores reconocen la importancia que los altos mandos (principalmente los ministros) se hagan cargo directamente de la reforma; pero con una comunicación mucho más afectiva, debido a los graves problemas de comunicación que afrontan la reforma. Después de haber visto la relación de Servir con los servidores de ambos Ministerios; el siguiente acápite abordará las estrategias de los servidores en caso la entidad en la que trabajan, en el caso imaginado que culmine el tránsito en Educación e Interior.

\section{c) Estrategias frente a la reforma}

Respecto a las estrategias de los servidores, se puede concluir que tanto los servidores del Minedu como del Mininter no son adversos al cambio y que estarían dispuestos a postular a su mismo puesto o a otro que se le presente. Así, encontramos a los servidores del Minedu quienes indican que:

"Si se aplica, me postulo y punto. No hay nada que discutir. Yo no soy adverso al cambio, hay gente que es adversa al cambio porque no está preparada o no tiene la experiencia o actitud debida que se requiere. Hay gente que le tiene miedo al cambio porque cree que va a fracasar [...]"

Así mismo,

"En teoría suena muy bonita: meritocracia, evaluaciones, mejores remuneraciones y seguro, pero la vaina es plasmarlo. Yo esperaría a ver cómo va a darse esa transición para ver si me quedo o no"

Su colega añade que:

"Yo me postularía porque tendría mayor estabilidad laboral porque con el CAS cada gestión que viene decide renovarte o no y eso no es saludable para nadie".

Y en el caso del Ministerio del Interior, hallamos que:

"me gusta trabajar para el Estado, pero no me veo trabajando 10 o 15 años en el mismo sitio. A mí me gusta tener la oportunidad de pasar por varias oportunidades para aprender, tener nuevas experiencias y retos. Algunos que sí quieren establecerse en el sector público, Servir los atrae por lo que le ofrece, el tema remunerativo y crecer profesionalmente. Depende de cómo percibas la LSC. En mi caso, varía de acuerdo a la generación".

"Claro que postularía. Pero, sin embargo, si yo quisiera postular a una plaza equis, es imposible, porque no cubriría ese perfil, las condiciones del diseño de ese perfil no se adecuan para captar a ese tipo de personal 276".

De esta forma, se encuentra que independientemente, de las capacidades que perciben de sí mismas, las personas entrevistadas no tendrían ningún problema en ser parte de un régimen laboral como el que ofrece Servir. En relación a la pregunta de si ha realizado acciones concretas sobre el tránsito al nuevo 
régimen, las personas entrevistadas no ofrecieron detalles sobre la pregunta puesto que al no "percibir" presente y continua la reforma, las dinámicas laborales no se han visto alteradas por dicho fenómeno. En otras palabras, los servidores siguen trabajando como si no existiera ninguna reforma del servicio civil, y sólo adoptarán alguna posición cuando la reforma sea inminente.

\section{Reflexiones finales}

A lo largo del texto, se ha buscado, en primer lugar, analizar la reforma del servicio civil peruano. De esta manera, se plantea que Servir se posiciona como una reforma que usa elementos de la NGP, dado que los intentos de formar una burocracia weberiana ha fracasado. Las características que han llevado a dicho planteamiento son que adquiere una estructura de estilo empresarial caracterizada principalmente por los "Gerentes Públicos” (o CEOs públicos).

Asimismo, aunque la esencia de la RSC se encuentra en la NGP, esta debe ser matizada por algunos elementos que nos indican que, aunque sea un enfoque empresarial, el objetivo es el ciudadano y existe un esfuerzo por introducir canales de transparencia y que se reflexione en torno a la ética pública. Sin embargo, los esfuerzos por mejorar la organización de la administración de los recursos humanos no han demostrado haberse adecuado a la realidad peruana. Por un lado, se han encontrado indicios que el patronazgo burocrático es capaz de infectar incluso a los gerentes públicos de Servir. Esto debido a que uno de ellos ha sido identificado como miembro de los "Cuellos Blancos del Puerto"6 (Expreso: 2 de octubre de 2018).

Del mismo modo, como manifestaba un informante del Ministerio de Educación: "Date cuenta que hubo este caso de las computadoras [compra en dicho ministerio por el que se interpeló al ministro Saavedra], caso de corrupción de las computadoras en esta compra de subasta inversa y eso era gente que había venido con el tema Servir". De esta forma, se evidencia que la falta de eficiencia no es un problema superado. Aunque no podemos generalizar por los casos antes mostrados, permite matizar los propósitos de Servir, como un importante avance, pero no como la "fórmula" que por sí sola vaya a solucionar todos los problemas de los que adolece la burocracia peruana. De esta manera, se plantean algunos comentarios e interrogantes sobre cómo podría mejorar Servir a la burocracia peruana.

En primer lugar, se abordó la cultura organizacional de los servidores públicos. En ambos ministerios y en todos los puestos se encuentra que existe una cultura del sacrificio, donde quien más tiempo permanezca en su puesto de trabajo y mientras mayores sean las labores que desempeñen, mayor será el prestigio ganado por sus compañeros. De caso contrario, un servidor, que por más eficaz que sea, salga a las cinco de la tarde (fin de la jornada laboral en el Estado peruano) es mal visto. Por dicha evidencia, se plantea las siguientes interrogantes: ¿De qué manera un mapeo de puestos y procesos bien estructurado podría lidiar con una cultura organizacional más dinámica? ¿Terminaría por vencer la cultura sobre las

\footnotetext{
${ }^{6}$ Banda criminal, llamada así por la Policía Nacional del Perú, que se caracteriza por ser una red de jueces y funcionarios públicos que utilizan sus puestos para beneficiarse del poder que estos le otorgan.
} 
normas, como lo han demostrado los estudios sobre patronazgo en Latinoamérica? O más bien, si se logra modificar la cultura organizacional del Estado, ¿Cómo se logrará captar prestigio social, el cual es base para las relaciones interpersonales?

Así mismo, se evidencia que el avance de los niveles de implementación de la reforma del servicio civil han sido procesos administrativos fantasma que no han ido informando los servidores sobre sus implicancias. De esta manera, se advierte que, de implementarse la reforma en un sistema organizacional que estuvo poco informado sobre el tema ocasionaría mayores tensiones en torno a la reforma.

Pese al problema antes mencionado, los servidores públicos demuestran interés por una reforma del servicio civil; pero admiten una gran desinformación entre sus colegas. De esta forma, Servir tiene un gran aliado para implementar la reforma: los propios servidores públicos. Al entrevistar a servidores con una carrera dentro de los ministerios de más de cuatro años, se halla una burocracia profesional, con altos niveles profesionales, lo cual les ha permitido mantenerse en el Estado. Por tal motivo, aquellos servidores no tienen ningún temor en transitar al nuevo régimen de servicio civil. Sin embargo, un aliado que más, que por ahora está jugando como enemigo potencial, es el sindicato. Aquella organización podría ser un aliado poderoso si es que se comunica adecuadamente los objetivos de la reforma del servicio civil. Finalmente es fundamental el apoyo de los "campeones" de las políticas de reforma: los ministros y altos cargos de los ministerios. 


\section{Bibliografía}

Arellano, D. (2004). "Nueva Gestión Pública. ¿Dónde está lo nuevo? Bases para el debate de la reforma”. Más allá de la reinvención del Gobierno: Fundamentos de la Nueva Gestión Pública y Presupuestos por Resultados en América Latina. Ed. David Arellano: Centro de Investigación y Docencia Económicas.

Barzelay, M. (2013). "La nueva gestión pública”. Nueva gestión Pública. Ed. Guillermo Cejudo: Biblioteca Básica de Administración Pública.

Boyer, J. (2014). "La Reforma del Empleo Público en el Perú - Análisis del nuevo Servicio Civil". Soluciones Laborales, $\mathrm{N}^{\circ} 77$.

Cortés J. y Prieto T. (2015). La reforma del servicio civil en el Perú: la profesionalización de la función pública.

Corrales, A. "Aportes del Cuerpo de Gerentes Públicos a la reforma del servicio civil en el Perú". CLAD.

El Peruano. Ley del Servicio Civil - Ley N 30057. Consulta: 4 julio de 2013.

Encinas, D. y Vergara, A. (2016). "Continuity by surprise: Explaining Institutional Stability in Contemporary Peru". Latin American Research Review, Vol. 51, No. 1, 159-180. https://doi.org/10.1353/lar.2016.0006

Expreso. Servir inicia proceso de expulsión a Parra. Martes 2 de octubre de 2018. https://www.expreso.com.pe/judicial/servir-inicia-proceso-de-expulsion-a-parra/

Gálves, A. (2017). "Parte I: Emprendedores del Estado: El Sistema Nacional de Inversión Pública y el surgimiento de los "perfileros" en los gobiernos locales”. Burócratas y Tecnócratas. La infructuosa búsqueda de la eficiencia empresarial en el Estado peruano del siglo XXI. Álvaro Gálvez y Álvaro Grompone: Instituto de Estudios Peruanos.

Gómez, C. (2006). "Burocracia y administración pública”. [en línea] Sociología. http://www.5campus.com/leccion/burocracia

Grindle, M. (2012). Jobs for the boys. Patronage and the state in comparative perspective. Harvard University Press. https://doi.org/10.4159/harvard.9780674065185

Iacoviello, M. y Zuvanic, L. (2005) "Diagnóstico Institucional de los Servicios Civiles de América Latina. Informe Final”. Diálogo Regional de Política, BID. Presentado en la V Reunión de la Red de Gestión y Transparencia de la Política Pública, Washington, DC, 17-18 de marzo.

Iacovello M., Strazza L. y Azzolina Y. (2011a). "Diagnóstico del servicio civil de Ecuador. Informe Final". Banco Interamericano de Desarrollo. 
Iacoviello, M. (2015). “Diagnóstico institucional del Servicio Civil en América Latina: Perú”. Banco Interamericano de Desarrollo.

Iacoviello, M., \& Chudnovsky, M. (2015). La importancia del servicio civil en el desarrollo de capacidades estatales en América Latina. $C A F$.

Martínez, S. (2016). "La Burocracia: Elemento de dominación en la obra de Max Weber". MISIÓN JURÍDICA Revista de Derecho y Ciencias Sociales. № 10, 141-154.

Martin-Barbero, J. (2010). "La reinvención patrimonial de América Latina". SPHERA PUBLICA Revista de Ciencias Sociales y de la Comunicación Número Especial, 291-309.

Martínez, R. (2005). “Servicio profesional de carrera. ¿Para qué?” Fundación Mexicana de Estudios Políticos Administrativos - Porrúa editores. México, D.F.

Petrella, C. (2007). "Análisis de la teoría burocrática. Aportes para la comprensión del modelo burocrático". Contribución para la Revista Electrónica de la Facultad de Ciencias Empresariales Universidad Católica del Uruguay.

Ramírez E. y García G. (2004) "En busca de un presupuesto por resultados en Chile: la reforma espontánea y el uso de instrumento para ligar el presupuesto al desempeño". Más allá de la reinvención del Gobierno: Fundamentos de la Nueva Gestión Pública y Presupuestos por Resultados en América Latina. Ed. David Arellano: Centro de Investigación y Docencia Económicas.

Ramió C. (2001) "Los problemas de la implantación de la Nueva Gestión Pública en las administraciones públicas latinas: modelo de Estado y cultura institucional”. Revista del CLAD Reforma y Democracia, №21.

Restrepo, M. (2009). “Burocracia, Gerencia Pública y Gobernanza”. Revista Diálogos de Saberes. N 30, 167-185.

Resico, M. (2015) "Neopatrimonialismo y patronazgo-clientelismo.Una revisión temática de la literatura". Revista Cultura Económica, № 90.

Schöler, Peter (s/f), Nueva Gestión Pública. Aportes para el buen gobierno. México D.F., Fundación Friedrich Naumann-Oficina Regional para América Latina, 45 p.

SERVIR. (2012). El Servicio Civil Peruano: Antecedentes, marco normativo actual y desafíos de la reforma.http://webcache.googleusercontent.com/search?q=cache:http://inst.servir.gob.pe/files/bibl ioteca/Web/Cieza\%2520-\%2520E1\%2520Servicio\%2520Civil\%2520Peruano.pdf 
SERVIR (2015). "SERVIR destaca avance de entidades en el tránsito a la reforma del servicio civil". Página web Servir. https://www.servir.gob.pe/servir-destaca-avance-de-entidades-en-el-transito-ala-reforma-del-servicio-civil/

SERVIR. (2016). Características del Servicio Civil Peruano. https://storage.servir.gob.pe/biblioteca/SERVIR-El_servicio_civil_peruano-Anx1.PDF

Sú Lay, C. (2015). Informe técnico N¹80-2015-SERVIR/GPGSC.

Ugarte, M. y Matos, R. "Análisis de los stakeholders respecto a la reforma del servicio civil”. XX Congreso Internacional del CLAD sobre la Reforma del Estado y de la Administración Pública, Lima, Perú.

Vergara R. y Rodríguez M. (2016). "Estudio sobre el estado de la literatura de la cultura organizacional en la administración pública desde el enfoque de análisis de contenidos”. Análisis, vol. 49, ํ9 90, 111-134. https://doi.org/10.15332/s0120-8454.2017.0090.05 